\title{
How iconic are Chinese characters?
}

\section{Citation}

LUK, GIGI, and ELLEN BIALYSTOK. 1999. "How iconic are Chinese characters?" Bilingualism: Language and Cognition 8 (1) (April): 79-83. doi:10.1017/S1366728904002081. http:// dx.doi.org/10.1017/S1366728904002081.

\section{Published Version}

doi:10.1017/S1366728904002081

\section{Permanent link}

http://nrs.harvard.edu/urn-3:HUL.InstRepos:11384941

\section{Terms of Use}

This article was downloaded from Harvard University's DASH repository, and is made available under the terms and conditions applicable to Other Posted Material, as set forth at http:// nrs.harvard.edu/urn-3:HUL.InstRepos:dash.current.terms-of-use\#LAA

\section{Share Your Story}

The Harvard community has made this article openly available.

Please share how this access benefits you. Submit a story.

Accessibility 


\section{Bilingualism: Language and Cognition}

http://journals.cambridge.org/BIL

Additional services for Bilingualism: Language and Cognition:

Email alerts: Click here

Subscriptions: Click here

Commercial reprints: Click here

Terms of use : $\underline{\text { Click here }}$

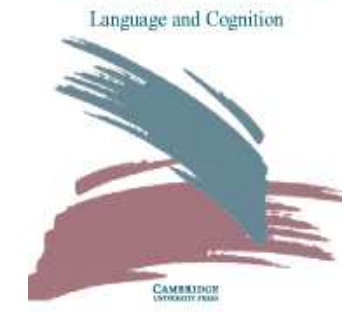

\section{How iconic are Chinese characters?}

GIGI LUK and ELLEN BIALYSTOK

Bilingualism: Language and Cognition / Volume 8 / Issue 01 / April 2005, pp 79 - 83

DOI: 10.1017/S1366728904002081, Published online: 04 April 2005

Link to this article: http://journals.cambridge.org/abstract S1366728904002081

How to cite this article:

GIGI LUK and ELLEN BIALYSTOK (2005). How iconic are Chinese characters?. Bilingualism: Language and Cognition, 8, pp 79-83 doi:10.1017/S1366728904002081

Request Permissions : $\underline{\text { Click here }}$ 
RESEARCH NOTE

\title{
How iconic are Chinese characters?
}

\author{
GIGI LUK \\ ELLEN BIALYSTOK \\ York University
}

\begin{abstract}
The study explores the notion that some Chinese characters contain pictorial indications of meanings that can be used to help retrieve the referent. Thirty adults with no prior knowledge of Chinese guessed the meanings of twenty Chinese characters by choosing between one of two photographs. Half of the characters were considered to be iconic and the other half was considered to be arbitrary. The proportion of correct guesses for iconic characters was high, but the proportion for arbitrary characters was at chance. These results show a distinction between characters based on the extent to which they have retained aspects of iconicity in reference to their concepts that can direct the reader to their meaning. The results have implications for using pictures to promote the understanding of the orthographic-semantic process in simple Chinese characters.
\end{abstract}

It is often heard that Chinese characters are pictographs that depict stylized representations of their meaning, but the reality is more complex. Although historically these characters developed from pictographs (Coulmas, 1991), the evolution to symbols reduced their complexity and decreased their degree of pictorial description (DeFrancis, 1989; Tang-Loaec and Colombel, 1995; Shu, Chen, Anderson, Wu and Xuan, 2003). DeFrancis (1989) claims that only $1 \%$ of all Chinese characters can be considered as pictographic. Most of these visually meaningful characters can be traced back to the graphical representations found on the oracle bone inscriptions (OBI) around 1200$1045 \mathrm{BCE}$, but even here the modern characters for these representations are significantly less iconic than their original forms. In a detailed analysis of 2,570 characters introduced in Chinese elementary schools between Grades 1 and 6, Shu et al. (2003) report that 9\% are pictographic or ideographic, although $26 \%$ of the characters taught in Grade 1 have this visual transparency.

There is also a general misapprehension about the processes involved in reading Chinese characters. Several studies have documented a role for phonological awareness in children learning to read Chinese (Ho and Bryant, 1997; Chan and Siegel, 2001; McBride-Chang and Kail, 2002), even though a more important role has been found for morphological awareness (Nagy, Kuo-Kealoha, Wu, Li, Anderson and Chen, 2002; McBride-Chang, Wat, Shu, Zhou and Wagner, 2003). Nonetheless, it remains the case that some Chinese characters have visual features that provide an indication of their meaning. For instance, the character 人 refers to human, and it looks like a person who is walking on two legs. This is not the case in alphabetic languages - the letters " $h-u-m-a-n$ " bear no resemblance to a real human being! Sound, more analogous to the written form of letter representations, is no better: except for the rare cases of onomatopoeia such as "meow" and "crunch", the meaning of English written words cannot be derived by their sounds. The potential for visual access to meaning is one of the most distinctive differences between character and alphabetic writing systems. Without the need to rely exclusively on sound structures as a proxy, readers can assimilate structural similarities between the character and its referent.

The latent iconicity of some characters might influence how children learn to read Chinese. In an interesting study, $\mathrm{Wu}$, Anderson, Li, Chen and Meng (2002) demonstrated that teaching young children the evolutionary link between a character and the object it represents was effective for reading instruction. By associating a picture of the intended object to the character, the lost iconicity of the character was "awakened" by the symbol-referent association. Therefore, such associations may increase the iconicity of characters by pointing to a physical similarity between the object and the character and provide a transition between the character and its meaning. The potential of this teaching strategy is particularly important in light of evidence from Shu et al. (2003) regarding the preponderance of iconic characters in first-grade curricula. Even adults may benefit from these visual connections: adult native English speakers were taught four symbol systems that were either alphabetic or logographic and found that logographic systems were significantly easier to learn to read (Muter and Johns, 1985).

Iconicity is the degree of visual similarity between a character and its referent. For the present study, the similarity was considered to be the degree of common structural configuration for both the character and the referent object. The decisions about iconicity were made subjectively by a native speaker of Cantonese as a first means of dividing the characters into the two classes. 
Table 1. Iconic and arbitrary characters used as experimental stimuli.

\begin{tabular}{|c|c|c|c|c|c|c|c|}
\hline \multicolumn{8}{|c|}{ Classification of characters } \\
\hline \multicolumn{4}{|c|}{ Iconic } & \multicolumn{4}{|c|}{ Arbitrary } \\
\hline Stimulus & $\begin{array}{l}\text { Cantonese } \\
\text { transcription }^{+}\end{array}$ & $\begin{array}{l}\text { English } \\
\text { translation }\end{array}$ & $\begin{array}{l}\text { Number } \\
\text { of strokes }\end{array}$ & Stimulus & $\begin{array}{l}\text { Cantonese } \\
\text { transcription }^{+}\end{array}$ & $\begin{array}{l}\text { English } \\
\text { translation }\end{array}$ & $\begin{array}{l}\text { Number } \\
\text { of strokes }\end{array}$ \\
\hline 弓 & gung 1 & bow & 3 & 4 & ngau4 & cow & 4 \\
\hline$Y$ & aa1 & branch & 3 & 犬 & hyun2 & canine & 4 \\
\hline$\pi$ & zaau2 & claw & 4 & 女 & neoi5 & female & 3 \\
\hline 田 & $\operatorname{tin} 4$ & field & 5 & 叉叉 & caa1 & fork & 3 \\
\hline 火 & fo 2 & fire & 4 & 手 & sau2 & hand & 4 \\
\hline 山 & saan1 & mountain & 3 & 土 & tou2 & soil & 3 \\
\hline 人 & jan4 & human & 2 & 日 & jat6 & sun & 4 \\
\hline 刃 & dou1 & knife & 2 & 牙 & ngaa4 & tooth & 4 \\
\hline 口 & hau2 & mouth & 3 & 水 & seoi2 & water & 4 \\
\hline 巾 & gan1 & pennant & 3 & 木 & muk6 & wood & 4 \\
\hline
\end{tabular}

${ }^{+}$Note: The Cantonese transcriptions were obtained from A Chinese Character Database: With word-formations phonologically disambiguated according to the Cantonese Dialect (Humanities Computing and Methodology Programme, 2003).

The criterion for classifying a character as iconic was the extent to which the character conveyed a stylized image of its meaning by depicting the inherent physical properties of the object and their overall configuration through the arrangement of the strokes. Arbitrary characters lack these structural correspondences. One of the primary purposes of the study was to validate these decisions by eliciting judgments from non-Chinese speakers.

The present study was aimed at exploring the inherent iconicity of some Chinese characters by associating them with pictures. One purpose was to validate a distinction between characters that are potentially iconic and those that are not in association with pairs of photographic stimuli. These results will also be used to develop materials for further research with early literacy instruction with Chinese children. A second purpose was to examine the extent to which the iconic properties of Chinese characters are accessible to non-Chinese speakers. These results have implications for general principles of literacy and literacy instruction. Early research in literacy has explored the effect of iconic writing systems on reading, but little attention has been paid to the structure of these systems and the information provided in the visual properties of the characters (Downing, 1973; Muter and Johns, 1985). The results will also contribute to notions of language instruction more broadly.

\section{Method}

\section{Participants}

Thirty university students (10 males and 20 females) were recruited as participants. The approximate mean age of the sample was 25 years 6 months (three participants did not disclose their ages). None of the participants had any prior knowledge of the Chinese language.

\section{Materials and design}

A set of 20 characters considered to consist of 10 iconic and 10 arbitrary characters was selected. All the characters referred to concrete objects and all were chosen to be comparable in visual complexity in that they were comprised of fewer than five strokes. A $t$-test confirmed that there was no significant difference between the number of strokes in the iconic $(M=3.2, s d=0.92)$ and the arbitrary $(M=3.7, s d=0.48)$ sets, $t(18)=-1.52$, $p>.14$. Table 1 presents the list of stimuli along with their Cantonese transcription, English translation and number of strokes.

In Chinese, each of these characters signifies a onesyllable word. Although frequency might be an important factor in character recognition for Chinese speakers, the participants in this study had no prior knowledge of Chinese, so the frequency of the character could not have much effect on their choice of which of two pictures it could indicate. Nonetheless, the frequencies of the chosen characters were obtained from a database (Humanities Computing and Methodology Programme, 2003). The frequency in the database was computed by obtaining the proportion of the frequency count of that character in the Corpus Unit to the total number of characters in that Unit. The Corpus Unit was constructed based on the Hong Kong region during the 1980s and 
the 1990s. A $t$-test comparing the frequencies of the iconic $(M=0.15, s d=0.35)$ and arbitrary characters $(M=0.08, s d=0.08)$ revealed that they were statistically the same, $t$ (Satterthwaite $\mathrm{df}=9.95)=0.67, p>0.50$. A Satterthwaite method of $t$-test is used to control the unequal variances of the frequencies, $F(9,9)=18.96$, $p<.0001$.

A further validation of the comparability of these characters was conducted on a group of 12 adults (not included in the main study) who had no familiarity with Chinese characters. The 20 characters were presented in a fixed random order. Participants were told that some characters provide clues to their meaning by their visual features and they were to try to guess the meaning of the 20 characters by looking only at the characters in isolation. Using exact meaning as the criterion, there were a total of two correct guesses from all 12 participants combined, both for iconic characters. These were for "human" and "mountain". This produces a mean score of 0.17 out of a maximum 10. The score for arbitrary characters was 0 . Using a liberal interpretation in which the response was considered correct if it was related to the semantic category of the correct term, the mean scores out of a maximum of 10 were 0.67 for iconic and 0.25 for arbitrary characters. Some examples are guessing "man" for "human", or "fork" instead of "branch". These numbers are all extremely low and not different from each other. Therefore, there was no difference between the characters in the two categories for their ability to elicit correct identifications on their own without any pictures as aids. This confirms that the characters were not inherently different from each other and that latent iconicity of the characters is not helpful in pointing to the meaning without explicit aids.

For the experiment, the testing materials were presented on a laptop computer using Microsoft PowerPoint. The task consisted of 20 slides, each containing a character and two photographs, labelled A and B. One of the photographs depicted the object named by the character and the other was a structurally similar photograph depicting an object from the same semantic category. For example, the character 手 "hand" was presented with photographs of a pair of hands and a pair of feet. The position of the target picture for each trial was counterbalanced between left and right.

Participants were instructed to guess which of the two photographs indicates the meaning of the character. They were explicitly told that some of the characters have features that could help them choose and some did not. The 20 slides were presented in a fixed random order. Participants were given a one-page answer sheet with a table showing the item number, character, and Picture $\mathrm{A}$ and $\mathrm{B}$ checkboxes, and were asked to check the box indicating the correct meaning. One point was assigned for each correct selection.

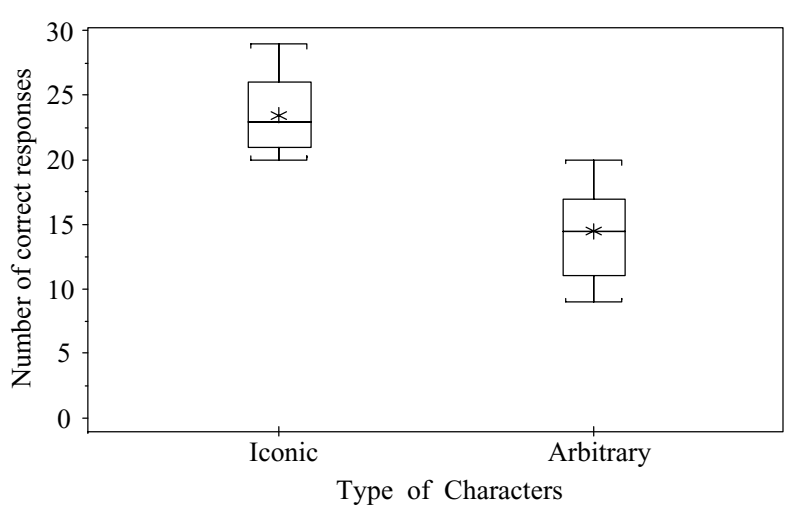

Figure 1. Comparison between the number of correct responses for iconic and arbitrary characters.

\section{Results}

The mean number of selections for the correct picture was higher for the ten iconic characters $(M=7.83, s d=$ 1.56) than it was for the arbitrary characters $(M=4.83$, $s d=2.07), \quad t(29)=6.35, p<.0001$. The graphical display of the comparison in Figure 1 shows that there was no overlap in the two distributions. Performance on the arbitrary characters was exactly at chance.

An item analysis was conducted to determine whether individual probabilities for each character were different from chance, irrespective of its designation as iconic or arbitrary. This analysis was based on proportion correct scores for each item. The proportion correct was the ratio of the number of correct responses to the total number of participants (i.e. 30). Then, each proportion correct was tested against the null hypothesis setting the proportion at 0.5 , which is the probability of getting the correct response by chance. All the proportions of correct responses for the iconic characters were significantly greater than chance, all $t s>|2.35|, p s<.03$ (two-tailed), except for the character 3 "bow", $t=1.90, n s$, which was not different from chance. Similarly, all the proportions of correct responses for the arbitrary characters were not different from chance, all $t \mathrm{~s}<|1.90|, p \mathrm{~s}>.06$ (twotailed), except for the character 牙 “tooth", $t=-2.35$, $p<.03$, where participants consistently chose the distracting photograph rather than the correct target. Although the character for tooth was considered to be arbitrary in that it shares no structural similarity with an image of a tooth, it happened that the distracting picture did correspond in a vague manner to the character. In both cases there was a protruding arm that could be interpreted as the relevant semantic cue, so participants chose this option more frequently than chance. Similarly, the structures of the strokes in the character "bow" was initially judged to be congruent with the actual structure of a bow, but the distracting picture of a sword appeared to be more similar. Thus, the correct response rate for this 
item was at chance, which contradicted to our predicted response rate for iconic items.

After excluding the two problematic items, the mean proportion correct was recalculated for each category. The adjusted scores out of 10 were 7.17 (1.56) for iconic characters and 4.53 (1.96) for arbitrary characters, a difference that remained significant, $t(29)=6.16$, $p<.0001$.

\section{Discussion}

Participants with no knowledge of Chinese characters could reliably select the correct meaning from two closely competing alternatives for characters that were considered to retain elements of iconicity in relation to their signified objects but were no better than chance on similar characters that were considered to be more arbitrary in their association with meaning. The findings are compelling because the objects were depicted using real-life photographs rather than artificial line drawings that would have emphasized the schematic similarity between the character and the object. Although the picture acted as a cue to possible meaning, it could not simply convey meaning itself because of the large differences in complexity and style between the characters and the pictures.

These results point to an important distinction between Chinese characters that have retained elements of their pictorial origins and those that have not. It is certainly not the case that Chinese characters are transparent pictographic representations of meaning; instead, characters differ in their visual accessibility to meaning and these visual features can be used to help determine meaning even by adults completely unfamiliar with Chinese characters. Without the picture, the items were equally opaque in their relation to meaning, but in conjunction with a picture, the iconic items could be readily interpreted. Some of the characters that we classified as arbitrary (e.g. "cow", "female", "hand" and "wood") have sometimes been considered to be iconic because they can be traced back to the OBI (DeFrancis, 1989), but the stylization of modern characters has led to the loss of this historical iconicity. The present results show the potential for reevoking the iconicity of some characters by linking them to a structurally similar picture of the signified object. Without these associations, all the characters would be arbitrary.

These results have important implications for using these features pedagogically for Chinese literacy instruction for both children and adults by showing the effectiveness of pictures for establishing associations between certain characters and their meaning. The results also build on the findings of Wu et al. (2002) by providing more detail about the type of characters that might be most amenable to this instructional approach. In their study, teaching young children to associate a concept to a symbol (such as a Chinese character) by associating pictures with the similar features in the symbol significantly increased the iconicity of characters. For students who are learning Chinese as a second language, the explicit association between Chinese characters and their referents could become an alternative method to facilitate their understanding of the configuration of the characters. Although the iconicity of some Chinese characters has been lost over time, traces of this feature can still be 'awakened' by explicit reference to the relation between the characters and pictures of the object they depict. Once awakened, this iconicity can provide a powerful tool for bringing children into literacy.

\section{References}

Chan, C. K. K. \& Siegel, L. (2001). Phonological processing in reading Chinese among normally achieving and poor readers. Journal of Experimental Child Psychology, 80, 23-43.

Coulmas, F. (1991). The writing systems of the world. Oxford: Blackwell.

DeFrancis, J. (1989). Visible speech: The diverse oneness of writing systems. Honolulu, HI: University of Hawaii Press.

Downing, J. (1973). Is literacy acquisition easier in some languages than in others? Visible Language, 7, 145-154.

Ho, C. S. \& Bryant, P. (1997). Learning to read Chinese beyond the logographic phase. Reading Research Quarterly, 32, 276-289.

Humanities Computing and Methodology Programme, Chinese University of Hong Kong. (2001). Hong Kong, Mainland China \& Taiwan: Chinese character frequency - A transregional, diachronic survey. Retrieved on July 19, 2004. Web site: http://www.arts.cuhk.edu.hk/Lexis/chifreq/

Humanities Computing and Methodology Programme, Chinese University of Hong Kong. (2003). A Chinese character database: With word-formations phonologically disambiguated according to the Cantonese dialect. Retrieved on September 30, (2004). Web site: http://humanum.arts.cuhk. edu.hk/Lexis/lexi-can/

Li, W., Gaffney, J. S. \& Packard, J. L. (eds.) (2002). Chinese children's reading acquisition: Theoretical and pedagogical issues. Norwell, MA: Kluwer Academic Publishers.

McBride-Chang, C. \& Kail, R. V. (2002). Cross-cultural similarities in the predictors of reading acquisition. Child Development, 73, 1392-1407.

McBride-Chang, C., Wat, C. P., Shu, H., Zhou, A. \& Wagner, R. K. (2003). Morphological awareness uniquely predicts young children's Chinese character recognition. Journal of Educational Psychology, 95, 743-751.

Muter, P. \& Johns, E. E. (1985). Learning logographies and alphabetic codes. Human Learning, 4, 105-125. 
Nagy, W. E., Kuo-Kealoha, A., Wu, X., Li, W., Anderson, R. C. \& Chen, X. (2002). The role of morphological awareness in learning to read Chinese. In Li et al. (eds.), pp. 59-86.

Shu, H., Chen, X., Anderson, R. C., Wu, N. \& Xuan, Y. (2003). Properties of school Chinese: Implications for learning to read. Child Development, 74, 27-47.

Tang-Loaec, R. \& Colombel, P. (1995). From pictograms to pinyin. The Unesco Courier, 48, 14-15.
Wu, X., Anderson, R. C., Li, W., Chen, X. \& Meng, X. (2002). Morphological instruction and teacher training. In Li et al. (eds.), pp. 157-173.

Received May 26, 2004

Revision received August 5, 2004

Revision accepted September 21, 2004 